\title{
Integrating Transport into Supply Chains: Vendor Managed Inventory (VMI)
}

\author{
Andrew Potter, Denis Towill and Stephen M. Disney \\ Logistics Systems Dynamics Group, Cardiff Business School \\ Cardiff University \\ Cardiff, CF10 3EU, UK
}

\begin{abstract}
Despite the importance of transport within the supply chain, it has traditionally been treated as a separate function within businesses. More recently there has been increased recognition that transport needs to be integrated into the supply chain. This chapter considers vendor managed inventory, and demonstrates how it can be used to improve both transport and supply chain performance. With VMI, inventory across the supplier/customer interface (including transport) is managed holistically. Analysis is carried out using simulation and through a case study from the UK grocery sector. Among the benefits identified are control of the bullwhip effect, improved customer service levels, lower transport costs and improved vehicle fill. In addition, it is found that VMI is particularly effective during times of pressure within the supply chain.
\end{abstract}

\subsection{Raison d'Etre}

Within supply chains, freight transport performs a crucial role at many stages in the delivery process, from moving raw materials to component manufacturers, subassemblers and Original Equipment Manufacturers (OEMs), through to delivering finished goods to the point of consumption. This importance is further illustrated by the fact that transport costs are typically equivalent to between $2 \%$ and $5 \%$ of a company's sales, although the figure is much higher for certain industrial sectors (Holcomb and Manrodt, 2000). The relationship between the supply chain and transport is dyadic. Transport is subject to the demands of the supply chain, yet the operation of the transport function (for instance, in terms of looking to reducing the cost of transport to a business) can influence the nature of these demands. Understanding both sides of this relationship is important for effective supply chain management. Indeed, there is often the need to optimally trade off supply chain performance against transport performance.

Under the circumstances it is therefore surprising that transport management is not often accorded higher importance within businesses. A common parochial viewpoint is that transport has to occur, and therefore costs should be minimised within the constraints enforced by the supply chain. Given that transport requirements represent derived demand, this trend is perhaps unsurprising. In looking to minimise transport costs, most companies seek to either create economies of scale in terms of shipping volume or make best use of the available equipment (Cubitt, 2002).

More recently the importance of leveraging improved performance from the transport operation has been recognised as providing an opportunity to increase flexibility whilst minimising the impact on transport costs (Stank and Goldsby, 2000). As a consequence it should be possible to reduce or eliminate the trade off between transport and supply chain performance. More detailed discussion on both contemporary transport management techniques and integration is provided by Potter and Lalwani (2005). One such supply chain response to this dilemma is vendor managed inventory (VMI), which is hence the focus of this chapter. Through simulation modelling and a real-world case study, we shall demonstrate 
Potter, A.T., Towill, D.R., and Disney, S.M., (2007), "Integrating transport into supply chains: VMI", Chapter 14 in "Trends in Supply Chain Design and Management: Technologies and Methodologies", Edited by Jung, H., Chen, F.F. and Jeong, B. Springer-Verlag, London, pp331-344, ISBN 1860-5168.

the potential for VMI to integrate transport more fully into the supply chain, thereby simultaneously delivering both transport and supply chain benefits.

\subsection{Vendor managed inventory}

Significant interest in the concept of VMI only developed as recently as the 1990s when companies looked to their supply chains in order to gain competitive advantage. While traditionally associated with the grocery sector (Andel, 1996), it has also been successfully implemented in a number of other areas, including the steel (Nolan, 1998) and electronics (Kuk, 2004) industries. There are a number of benefits that VMI brings to the supply chain, particularly regarding dynamic behaviour, customer service, inventory and asset utilisation. A fuller description of the development of VMI and its expected benefits is provided by Disney (2001).

A simple diagram of a VMI relationship can be found in Figure 1. Here the supplier is in control of the customer's inventory with the aim of ensuring that predetermined service levels are maintained. Hence the vendor takes all the replenishment decisions, despatching a quantity of product that may be fixed or variable according to the control system used (Waller et al., 1999). So in this respect the customer effectively takes a passive role in the supply chain.

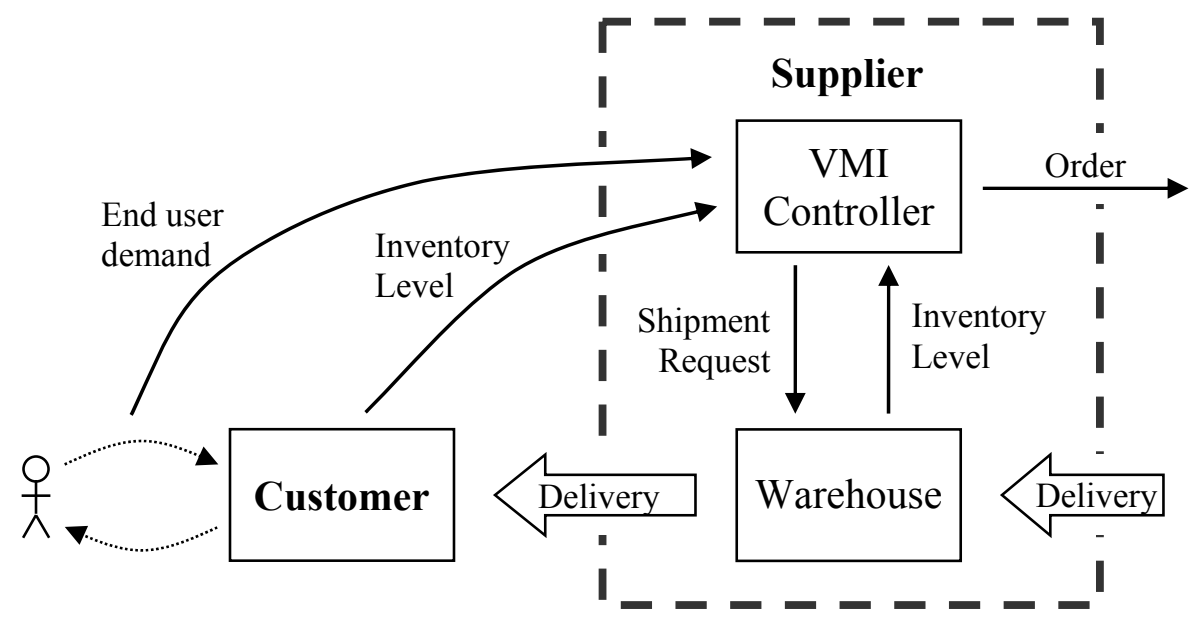

Fig. 1.1. Vendor Managed Inventory system (adapted from Waller et al., 1999)

For the particular control system studied herein, customer replenishment is triggered when the customer stock level reaches a specified point. This reorder point is based on both the average demand during the transport lead time and a safety stock to cover demand variability (Kaipia et al., 2002). This triggers a despatch quantity which, if it is to make the best use of transport, should be based around full vehicle loads. So at an individual business level, VMI appears to contradict the ethos of lean production, with batched rather than just-in-time deliveries. However, by taking a holistic supply chain view, VMI can be considered complementary. Indeed, as will be discussed shortly, VMI can reduce system inventory levels and smooth demand signals along the supply chain.

For VMI to be successful, information on inventory levels and end user demand needs to be transparently transferred between both parties (Andel, 1996). Depending upon the sector in which VMI is operating, this may represent significant quantities of data. Such a large volume is needed to cope with a wide range of SKU's and sales to many possible destinations. The recent developments in Information and Communication Technology are important in facilitating this transfer, thereby reducing the transaction cost.

To date there have been very few studies considering how the transport function can be exploited within the context of a VMI supply chain. This is despite the undoubted transport benefits that proper implementation of VMI can bring. For example, it is recognised that VMI enables full vehicle loads to be moved every time (Waller et al., 1999), thus pleasing the vociferous "green" lobby. There is also flexibility within transport planning suggesting the potential to smooth the variability of deliveries (Lee, 2000). This flexibility has been shown to deliver lower supply chain costs and inventory reductions for 
Potter, A.T., Towill, D.R., and Disney, S.M., (2007), "Integrating transport into supply chains: VMI", Chapter 14 in "Trends in Supply Chain Design and Management: Technologies and Methodologies", Edited by Jung, H., Chen, F.F. and Jeong, B. Springer-Verlag, London, pp331-344, ISBN 1860-5168.

suppliers and customers (Çetinkaya and Lee, 2000, and Cheung and Lee, 2002). However only le Blanc et al. (2004) start to address the specific issue of VMI and transport, showing how the flexibility in inventory control coupled with an optimised transport network can increase vehicle fill and reduce transport costs.

This chapter aims to provide further insights into the impact of VMI on transport, whilst also considering the wider impact on supply chain performance measures. Firstly, insight is generated through the use of a simulation model based on a generic production and inventory control system, following which a case study from the grocery industry in the UK is presented. More exhaustive details on these aspects of the research can be found in Disney et al. (2003), Potter (2005) and Potter et al. (2005).

\subsection{VMI and transport: Simulation study}

To better depict the VMI scenario, the model (VMI-APIOBPCS) developed and studied in detail in terms of inventory, bullwhip and customer service level by Disney (2001) will be used. The Automated Pipeline Inventory and Order Based Production Control System was first proposed by John et al. (1994) and it has been found to meet the four criteria for good research (Guba and Lincoln, 1994). APIOBPCS has internal validity (Olsmats et al., 1988), external validity (Berry et al., 1995), reliability (Anderson et al., 2000) and finally objectivity (Edghill et al., 1988). The development of the VMI model has followed from consideration and conceptualisation of the published literature plus the monitoring of industrial practice (Edghill et al. 1988). This model has also been used as the basis for a VMI decision support system (DSS) implemented in a field trial within a grocery supply chain in Finland (Disney et al., 2001).

The single SKU causal loop diagram of the model is illustrated in Figure 1.2. It was then translated into a spreadsheet model through the use of the associated difference equations. These can be found in Disney et al. (2003), along with recommended parameter settings to match various deliver strategies. The model has been developed to allow the despatch of any number of vehicles from the supplier to the customer, provided each truck is full. This reflects actual practice within the case study, detailed later. Two different scenarios have been analysed in this study:

- Traditional supply chain - this will form the baseline scenario.

- VMI control - using the VMI controller to manage inventory at the customer and only despatching in full vehicle loads.

In terms of demand, this was represented by a normally distributed random signal of mean 1 and standard deviation 0.2. In each scenario, all target inventories were set equal to zero. Vehicle capacity was varied between 0.3 and 8 units, i.e., $30 \%$ to $800 \%$ of mean demand. The nature of the simulation model is such that, providing all values are scaled by the same amount, the relevant results will be unchanged. By choosing an average demand of 1 , it is possible to easily see the ratio to other settings (such as demand variability, vehicle capacity, etc). Therefore translating the results to other settings becomes easier. The focus of performance measures is on bullwhip, fill rate at the customer, transport demand and vehicle fill.

Table 1.1 contains the simulation results for the non-transport performance measures. It can be seen that VMI delivers consistently lower levels of demand amplification than the traditional scenario, findings that are in line with those reported by Disney and Towill (2003). In both scenarios the level of amplification is independent of the vehicle capacity. With VMI, the order rule evaluates system inventory and so transport batch sizes do not influence the ordering rule. In terms of customer fill rate, VMI offers service level improvements for all of vehicle capacities simulated. While the level of service is constant for the traditional scenario, under VMI the fill rate is dependent upon the size of the vehicle. This is because the use of larger vehicles increases the average inventory holding at the customer, therefore reducing the probability of an order not being fully satisfied. 


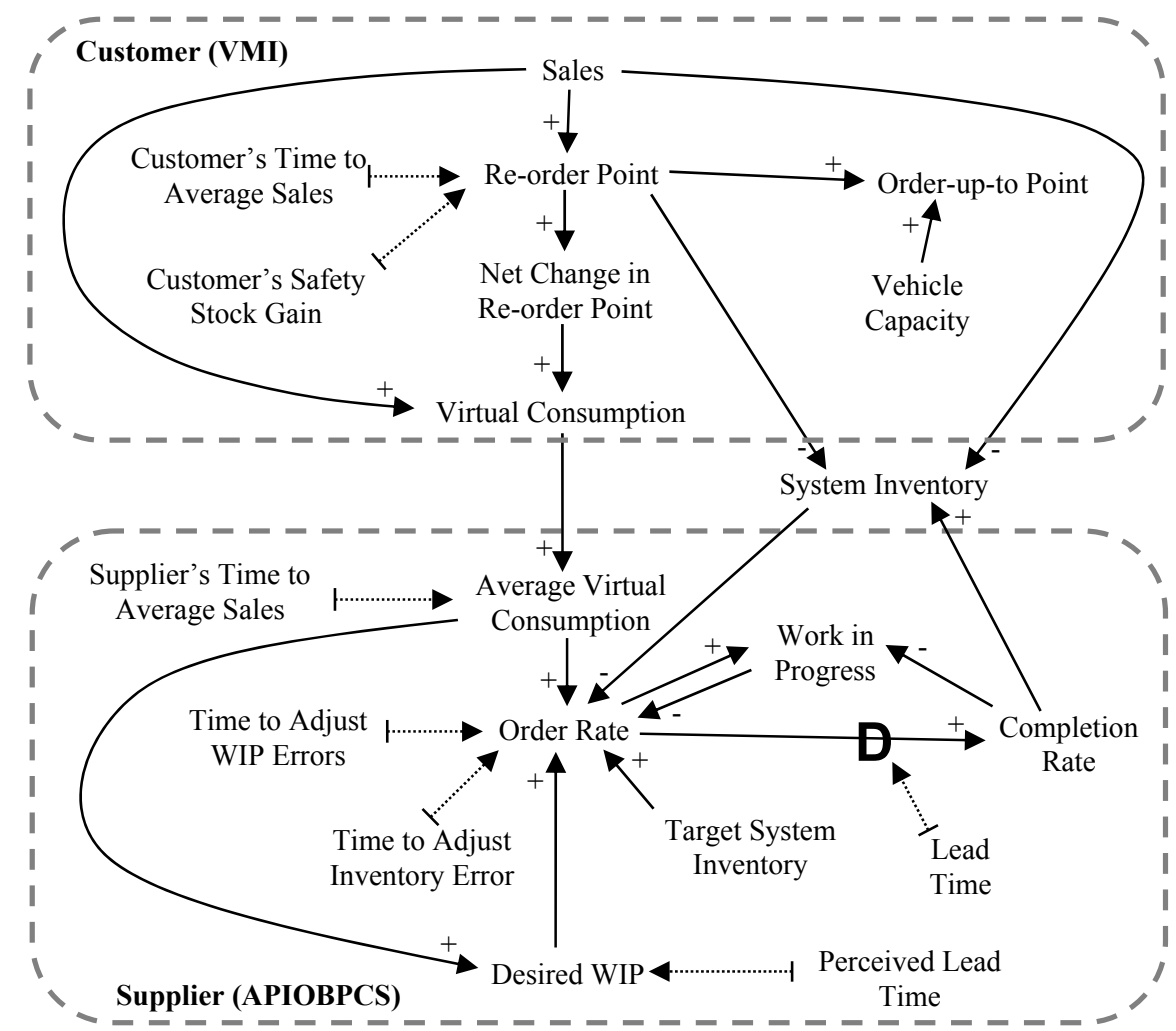

Fig. 1.2. Causal loop diagram of the VMI-APIOBPCS system (Disney, 2001)

Table 1.1. Performance measures for bullwhip and fill rate

\begin{tabular}{|c|c|c|c|c|c|c|c|c|}
\hline & \multicolumn{7}{|c|}{ Vehicle Capacity } & \multirow{2}{*}{ Comments } \\
\hline & 0.3 & 0.5 & 1 & 2 & 4 & 6 & 8 & \\
\hline \multicolumn{9}{|l|}{ Bullwhip } \\
\hline Traditional & 0.69 & 0.69 & 0.70 & 0.67 & 0.67 & 0.67 & 0.67 & \multirow{2}{*}{$\begin{array}{l}\text { - Bullwhip independent } \\
\text { of vehicle capacity } \\
\text { - VMI reduces bullwhip } \\
\text { in all scenarios }\end{array}$} \\
\hline VMI & 0.48 & 0.49 & 0.47 & 0.48 & 0.50 & 0.49 & 0.49 & \\
\hline \multicolumn{9}{|c|}{ Customer Fill Rate (\%) } \\
\hline Traditional & 83.5 & 83.5 & 83.5 & 83.7 & 83.5 & 83.7 & 83.9 & \multirow{2}{*}{$\begin{array}{l}\text { - VMI improves fill rate } \\
\text { in all scenarios } \\
\text { - Performance related to } \\
\text { capacity under VMI }\end{array}$} \\
\hline VMI & 90.2 & 92.6 & 96.0 & 98.0 & 99.0 & 99.3 & 99.5 & \\
\hline
\end{tabular}

Figure 1.3 illustrates the impact of VMI on transport demand and vehicle fill. With VMI, transport demand becomes equal to average demand divided by the vehicle capacity. This reflects the system always making despatches in full vehicle loads. Consequently, VMI always offers a reduction in transport demand, with the savings increasing with vehicle capacity. A reduction of $13.2 \%$ is achieved when vehicle capacity equals 0.3 units (30\% of average demand), while this increases to $87.5 \%$ when capacity is 8 times average demand. Without VMI, average transport demand per period levels out at 1 because the traditional supply chain requires despatches to be made every time period, regardless of the volume being shipped. This also has a negative impact on vehicle fill, which falls to just $12.5 \%$ when vehicle capacity is 8 times average demand. Such an approach is similar to lean supply, requiring deliveries just-in-time. In Japan, the adoption of such working practices led to the use of smaller delivery 
vehicles, which increased vehicle fill but had a negative impact on traffic congestion (Nieuwenhuis, 1994).

This section has shown that VMI has the potential to offer significant benefits, both in terms of the supply chain performance and the transport operations and costs contained within. VMI thus avoids a conflict between transport and supply chain performance, and such benefits materialise because VMI integrates decision making in inventory control and transport management to enable greater flexibility to either schedule despatches more effectively or use batching rules to maximise payload utilisation. However, these results have been obtained from a simulation model. In order to understand more fully the impact of VMI within a real-world situation, a more complex real-world case study will now be presented.

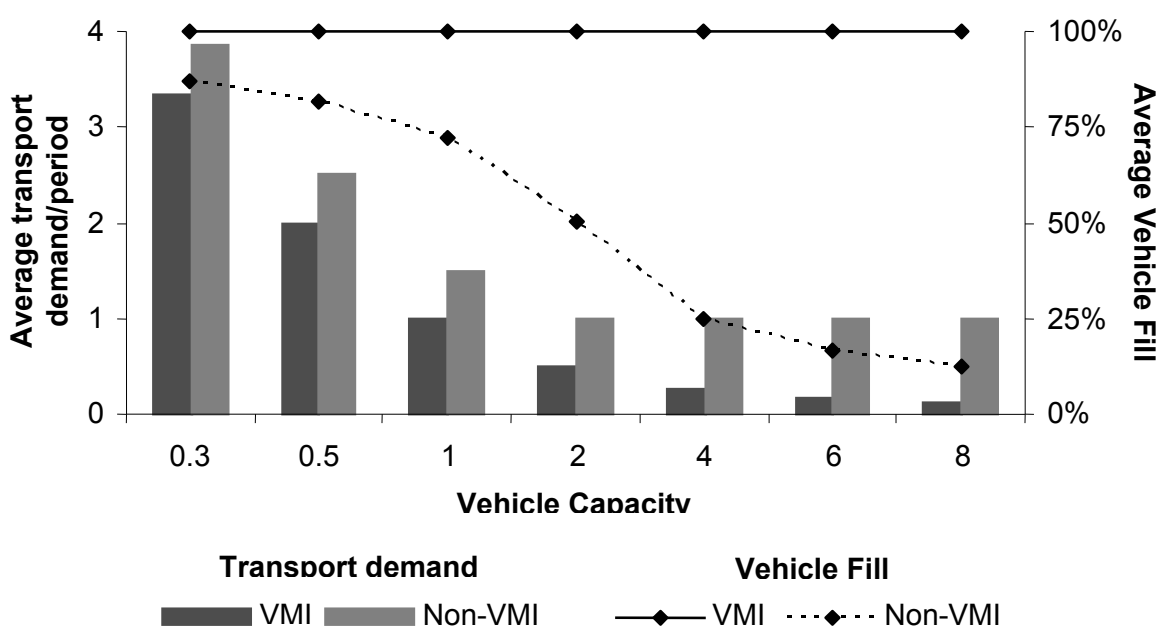

Fig. 1.3. Transport demand and vehicle fill performance

\subsection{VMI and transport: Case study}

The case study in this chapter is drawn from the grocery sector in the UK, and relates to the relationship between a soft drinks manufacturer and the retailers it supplies (Potter, 2005). The case study not only confirms the findings from the simulation model but also builds upon the results by considering a more complicated situation with multiple value streams interacting with each other, plus a greater emphasis on customer service. Within the UK grocery sector, it has been recognised that the retailers place immense pressure on suppliers to deliver on time, thus distorting their logistics system behaviour so as to avoid punitive fines (Towill, 2005). Clearly, this is a factor to keep in mind during the investigations. Appropriate field data were collected and analysed via the Quick Scan Audit Methodology (Naim et al., 2002), which brings together process mapping, data analysis, interviews and detailed questionnaires in a structured and triangulated evidence procedure so as to gain an in-depth understanding of actual supply chain processes. Real-world performance measures were similar to those used in the foregoing simulation study, with a focus on dynamic behaviour, inventory, customer service levels and transport efficiency.

Figure 1.4 shows the resultant process map detailing the actual VMI relationship. There are effectively three replenishment cycles within the supply chain. The first relates to the restocking of individual stores with the ordering system producing at least one order per day for each site. This demand is then fulfilled from the Distribution Centre (DC). Typically, deliveries will arrive within 24 hours of the order being placed. 


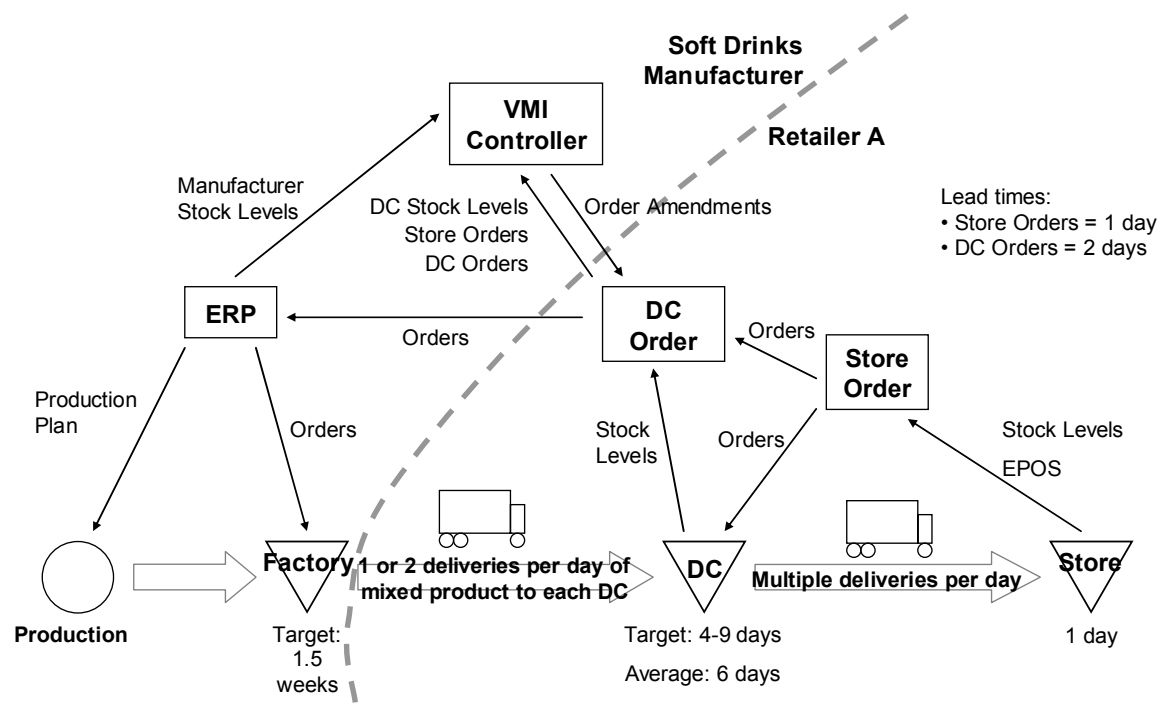

Fig. 1.4. Process map of the VMI relationship

The second cycle relates to the replenishment of the DCs by the supplier, which includes the VMI relationship. The initial orders are generated by the DC Order system. Once this has taken place, there is then the scope for the VMI controller (a human decision maker in this Case Study) to adjust the orders, while simultaneously considering inventory levels both within the DCs and at the manufacturer. When the controller is satisfied that the orders can be met, these orders are confirmed and sent via EDI to the ERP system of the manufacturer. Typically, there is a two-day lead time. Transport for the delivery is arranged by the retailer. Stock levels at the DC vary between 4 - 9 days of average demand.

The final cycle relates to actual production at the soft drinks manufacturer. This is driven by the ERP system and planned around a desirable batch size of 7,500 cases, although sometimes 'half batches' of 3,750 cases are made. Actual production depends upon inventory levels for finished goods and raw materials, as well as constraints relating to the cleaning of the production line and the sequence in which products can be made. Typically, the target is to hold 1.5 weeks of finished goods stock at the factory, as detailed by Potter et al. (2005). In terms of the performance of the supply chain, Table 1.2 details the actual order variability, inventory variability (for comparison purposes, both are expressed as the coefficient of variation) and bullwhip effect. Due to a lack of available field data, comparisons of this last measure can only be made across the soft drinks manufacturer.

We surprisingly find that more bullwhip is introduced into the VMI supply chain. This appears to contradict our expectations from the simulation findings, where around a 30\% reduction was achieved. Further investigation shows that the reason the performance has decreased is related to the Every Day Low Pricing (EDLP) policy adopted by the VMI retailer. Because incoming orders are reasonably stable and there is flexibility in managing the DC inventory through VMI, production need not be on a regular basis in order to ensure adequate safety stocks. Hence strategic supplier decisions can be taken to produce extra stock during one week and deliberately plan to sacrifice the next week's production. Thus, there is greater certainty that the inventory cover will be sufficient to handle the relatively small variations in demand. This procedure helps maintain service levels for non-VMI customers by the simple strategy of reversing the scheduling priorities for "baseline" (VMI products in this case) and "surge" (non-VMI products) demand (Christopher and Towill, 2002). For our scenario, the switch produces both higher plant utilisation and better service levels simultaneously.

Inventory performance is measured in terms of the variability of inventory levels. The values in Table 1.2 indicate that there is a lesser degree of variability within the VMI supply chain than observed in the non-VMI supply chain. As explained earlier, one reason for this is the low level of variability in incoming demand with the VMI retailer. Additionally, the fact that the VMI controller is effectively managing inventory in the DC as well, which helps dampen changes in inventory level when compared against the non-VMI supply chain. Furthermore, there is a close relationship between the batch sizes and 
Potter, A.T., Towill, D.R., and Disney, S.M., (2007), "Integrating transport into supply chains: VMI", Chapter 14 in "Trends in Supply Chain Design and Management: Technologies and Methodologies", Edited by Jung, H., Chen, F.F. and Jeong, B. Springer-Verlag, London, pp331-344, ISBN 1860-5168.

average demand for each product in the VMI supply chain. With demand being relatively predictable, it is possible for the manufacturer to pace production against demand and therefore minimise the amount of inventory required to be held. However, the alignment for non-VMI products is not as good, leading to increased variability in stock holding.

Table 1.2. Bullwhip and inventory performance in the UK Grocery case study supply chains

\begin{tabular}{|c|c|c|c|c|c|c|c|}
\hline \multirow[b]{2}{*}{$\begin{array}{l}\text { Product } \\
\text { Volume }\end{array}$} & \multicolumn{3}{|c|}{$\begin{array}{c}\text { VMI } \\
\text { Supply Chain }\end{array}$} & \multicolumn{3}{|c|}{$\begin{array}{c}\text { Non-VMI } \\
\text { Supply Chain }\end{array}$} & \multirow{2}{*}{ Comments } \\
\hline & High & Med & Low & High & Med & Low & \\
\hline \multicolumn{8}{|c|}{ Coefficients of Variation (CVs) } \\
\hline EPOS & 0.186 & 0.250 & 0.325 & & & & \multirow{4}{*}{$\begin{array}{l}\text { - Low CVs for VMI due } \\
\text { to EDLP } \\
\text { - } \begin{array}{l}\text { Promotions in non-VMI } \\
\text { retailer }\end{array} \\
\text { - } \begin{array}{l}\text { Batching in production } \\
\text { decisions }\end{array}\end{array}$} \\
\hline Order & 0.314 & 0.344 & 0.442 & 0.848 & 0.784 & 1.158 & \\
\hline Inventory & 0.600 & 0.732 & 1.077 & 2.043 & 1.435 & 2.565 & \\
\hline Production & 0.873 & 0.824 & 1.404 & 1.694 & 1.432 & 1.723 & \\
\hline \multicolumn{8}{|c|}{ Amplification Ratio } \\
\hline Order & 1.69 & 1.38 & 1.36 & & & & \multirow{3}{*}{$\begin{array}{l}\text { VMI introduces more } \\
\text { bullwhip due to EDLP } \\
\text { reducing demand } \\
\text { uncertainty }\end{array}$} \\
\hline Production & 2.78 & 2.40 & 3.17 & 1.99 & 1.83 & 1.49 & \\
\hline Inventory & 1.91 & 2.13 & 2.44 & & & & \\
\hline
\end{tabular}

Customer service levels are measured on the basis of the number of cases delivered against the number of cases ordered. The average levels for both retailers are fairly similar at $99.2 \%$ and $99.1 \%$ for the VMI and non-VMI supply chains. However, the weekly variability in service level is reduced by $41 \%$ under VMI, giving greater consistency to the customer. From Table 1.1, it can be seen that the simulation model suggested an improved customer service level under VMI, although the level of this benefit diminishes as vehicle capacity decreases. But it should be remembered that suppliers in the UK grocery industry are under immense pressure from retailers to maintain customer service levels (Towill, 2005). Consequently, the customer service figures in the Case Study are likely to be affected, thus masking the true benefits from the use of VMI.

In terms of transport performance, the main metric used by the case study company was vehicle fill. The trend in vehicle fill across a 12-month period is shown in Figure 1.5. Also shown is the despatched volume during the same period, which is reflective of transport demand. Vehicle fill is generally better for the VMI retailer over the non-VMI retailer, confirmed by the median values of $99.8 \%$ and $99.0 \%$. There is also greater consistency as reflected in $78 \%$ less variability in weekly vehicle fill values. If the level of vehicle fill achieved in the non-VMI supply chain was replicated in the VMI supply chain, transport demand would have been a significant $4 \%$ higher.

In terms of a comparison with the simulation model, average demand is greater than vehicle capacity. The findings where vehicle capacity equals $30 \%$ of average demand appear to offer the best comparison. The model predicted an increase of $13 \%$ in vehicle fill, with a $13 \%$ reduction in transport demand as a result. The case study fails to match this level of benefit for several reasons. The model only despatches full vehicle loads, whereas the commercial pressures in the Case Study sometimes requires the despatch of vehicles with less than a full load. Also, the non-VMI supply chain includes transport batching in the order rule, thereby inflating vehicle fill percentages. 


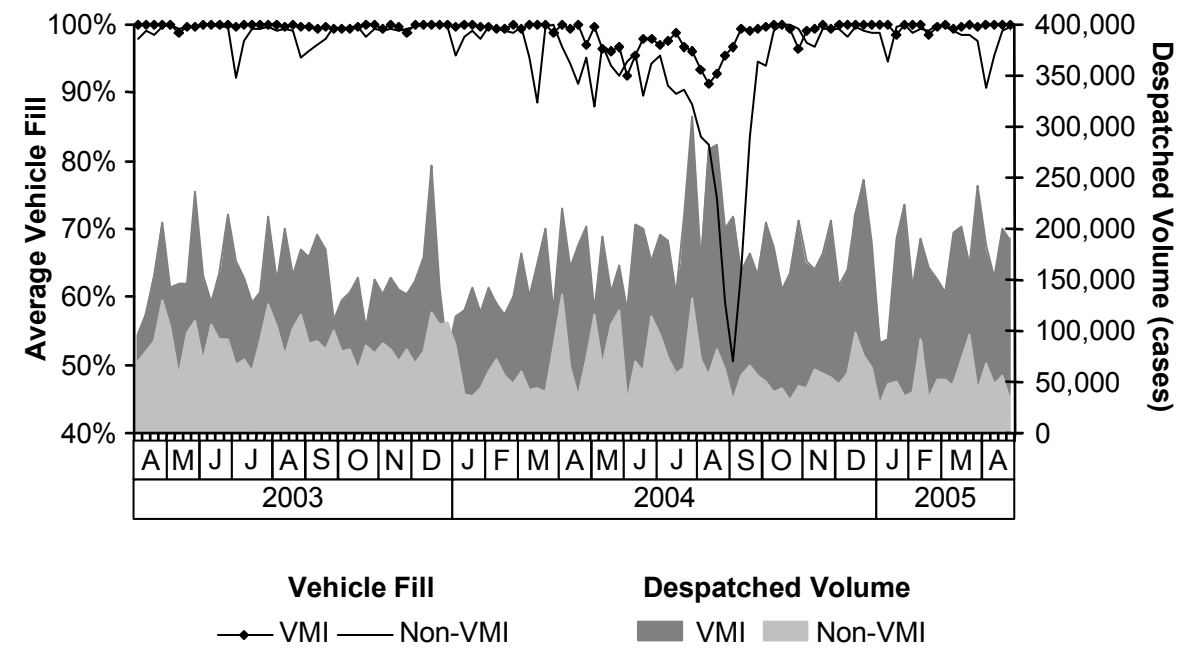

Fig. 1.5. Average vehicle fill percentages for deliveries in both supply chains

VMI appears to particularly bring user benefits during times of high pressure in the supply chain. For example, during July and August 2003, the UK experienced a heat wave, leading to a big surge in demand for soft drinks. This placed pressure on the fixed production capacity, since the demand from all retailers increased. The consequential impact on vehicle fill was more significant for the non-VMI retailer, with a minimum value of $50.5 \%$. The corresponding minimum in the VMI supply chain is $91 \%$. One of the main reasons for this much better result is the flexibility in inventory control enabling the substitution of products which were unavailable at the supplier for ones that were in stock. This helped maintain high vehicle fill. The negative impact on customer service performance from amending orders was limited as, by having visibility of stock throughout the retailer's DC network, the VMI Controller could target deliveries to where products were needed most.

\subsection{Conclusions \& Guidelines to Practitioners}

Transport performs a crucial role within supply chains by making goods available where the customer requires them. Traditionally, there has been a view that transport of goods just happens and that businesses should look to maximise its importance within the constraints imposed by the supply chain. However, this overlooks the fact that the relationship between supply chains and transport is a two-way process. Nowadays, there is increased interest in integrating transport within supply chains as a means of improving trade-offs in value stream performance.

A supply-chain-centred approach to achieving this objective is VMI. By holistically managing inventory, VMI enables full vehicle loads to be moved without affecting the dynamic performance of the production system. The impact of introducing VMI has been evaluated through both a simulation model and a case study. Performance was particularly compared in the areas of supply chain dynamics, customer service, transport demand and vehicle fill. A summary of the main findings can be found in Table 1.3. The simulation model results are limited to just those where vehicle capacity is $30 \%$ of average demand, as this represents the closest comparison to the case study. As can be seen, VMI offers the potential to deliver improvements to all of these areas and gets around the trade-off between transport and supply chain performance often found in contemporary logistics management. However, another benefit of VMI that became particularly apparent during the case study was that of more flexibility. The supplier has the opportunity to manage both despatches and production so as to deliver benefits to VMI and non-VMI supply chains via the reversal of "baseline" and "surge" production scheduling. 
Potter, A.T., Towill, D.R., and Disney, S.M., (2007), "Integrating transport into supply chains: VMl", Chapter 14 in "Trends in Supply Chain Design and Management: Technologies and Methodologies", Edited by Jung, H., Chen, F.F. and Jeong, B. Springer-Verlag, London, pp331-344, ISBN 1860-5168.

Table 1.3. Impact of VMI implementation on performance measures

\begin{tabular}{|c|c|c|c|}
\hline $\begin{array}{c}\text { Performance } \\
\text { Measure }\end{array}$ & $\begin{array}{c}\text { Simulation Results } \\
\text { (Vehicle Capacity }=\mathbf{0 . 3})\end{array}$ & $\begin{array}{c}\text { Case Study } \\
\text { Findings }\end{array}$ & Comments \\
\hline Bullwhip & $30 \%$ reduction & $\begin{array}{c}\text { At least } 30 \% \\
\text { increase }\end{array}$ & $\begin{array}{c}\text { Supplier has greater certainty } \\
\text { with VMI. Therefore, creates } \\
\text { flexibility in production to } \\
\text { maintain service to all } \\
\text { customers, introducing extra } \\
\text { demand amplification. }\end{array}$ \\
\hline $\begin{array}{c}\text { Customer } \\
\text { service }\end{array}$ & $7 \%$ increase & Equal & $\begin{array}{c}\text { Immense pressure from grocery } \\
\text { retailers to maintain service } \\
\text { level. VMI performance more } \\
\text { consistent in case study. }\end{array}$ \\
\hline $\begin{array}{c}\text { Transport } \\
\text { demand }\end{array}$ & $13.2 \%$ decrease & $4 \%$ decrease & $\begin{array}{c}\text { Some benefit of VMI offset by } \\
\text { improved vehicle fill for non- } \\
\text { VMI supply chain. }\end{array}$ \\
\hline Vehicle fill & $13 \%$ increase & Equal & $\begin{array}{c}\text { Non-VMI supply chain includes } \\
\text { rounding. Also customer } \\
\text { service pressures to despatch } \\
\text { less than full vehicles. VMI } \\
\text { more consistent and better at } \\
\text { peak times. }\end{array}$ \\
\hline
\end{tabular}

There are two directions for future extensions of this work. In relation to VMI, there is a need to increase the complexity of the simulation modelling to take into consideration a wider range of scenarios. Alternative case studies from both within the grocery sector and elsewhere will broaden the understanding of real-world experience with VMI, and particularly in relation to transport. As can be seen, the simulation model and real world results do differ for certain performance measures, and there is a need to understand whether this is a unique case or a more general trend. The second direction is to look more widely at transport integration and identify other managerial approaches that can be adopted. This recognises that VMI will not be applicable in all circumstances, thereby requiring other approaches to further integrate transport into the supply chain.

\subsection{References}

Andel T (1996) Manage inventory, own information. Transport and Distribution 37(5):54-58.

Anderson EG, Fine CH, Parker GG (2000) Upstream volatility in the supply chain: The machine tool industry as a case study. Production and Operations Management 9(3):239-261.

Berry D, Naim MM, Towill DR (1995) Business process re-engineering an electronic products supply chain. IEE Proceedings - A 142(5):395-403.

Çetinkaya S, Lee CY (2000) Stock replenishment and shipment scheduling for vendor-managed inventory systems. Management Science 46(2):217-232.

Cheung KL, Lee HL (2002) The inventory benefit of shipment coordination and stock rebalancing in the supply chain. Management Science 48(2):300-306.

Christopher M, Towill DR (2002) Developing market specific supply chain strategies. International Journal of Logistics Management 13(1):1-14.

Cubitt B (2002) Cut the fat on freight. APICS - The Performance Advantage 12(3):42-45.

Disney SM (2001) The production and inventory control problem in Vendor Managed Inventory supply chains. Ph.D. Thesis, University of Wales, Cardiff.

Disney SM, Holmström J, Kaipia R, Towill DR (2001) Implementation of a VMI production and distribution control system. Proceedings of the 6th International Symposium on Logistics, Saltzburg, 187-194.

Disney SM, Towill DR (2003) Vendor managed inventory and bullwhip reduction in a two-level supply chain. International Journal of Operations and Production Management 23(6):625-651.

Disney SM, Potter AT, Gardner B (2003) The impact of vendor managed inventory on transport operations. Transportation Research Part E: Logistics and Transportation Review 39(5):363-380.

Edghill J, Olsmats C, Towill DR (1988) Industrial case-study on the dynamics and sensitivity of a close coupled production-distribution system. International Journal of Production Research 26(10):1681-1693.

Guba EG, Lincoln YS (1994) Competing paradigms in qualitative research. In Denzin NK and Lincoln YS (Eds.) Handbook of Qualitative Research. SAGE Publications, London. 
Potter, A.T., Towill, D.R., and Disney, S.M., (2007), "Integrating transport into supply chains: VMl", Chapter 14 in "Trends in Supply Chain Design and Management: Technologies and Methodologies", Edited by Jung, H., Chen, F.F. and Jeong, B. Springer-Verlag, London, pp331-344, ISBN 1860-5168.

Holcomb MC, Manrodt KB (2000) The shippers' perspective: Transportation and logistics trends and issues. Transportation Journal 40(1):15-25.

John S, Naim MM, Towill DR (1994) Dynamic analysis of a WIP compensated decision support system. International Journal of Manufacturing System Design 1(4):283-297.

Kaipia R, Holmström J, Tanskanen K (2002) VMI: what are you losing if you let your customer place orders? Production Planning and Control 13(1):17-25.

Kuk G (2004) Effectiveness of vendor-managed inventory in the electronics industry: determinants and outcomes. Information and Management 41(5):645-654.

le Blanc HM, van Krieken MGC, Fleuren HA, Krikke HR (2004) Collector Managed Inventory: A Proactive Planning Approach to the Collection of Liquids Coming from End-of-Life Vehicles. CentER Applied Research Discussion Paper No. 2004-22, Tilburg University.

Lee HL (2000) Creating value through supply chain integration. Supply Chain Management Review 4(4):30-36.

Naim MM, Childerhouse P, Disney SM, Towill DR (2002) A supply chain diagnostic methodology: determining the vector of change. Computers and Industrial Engineering 43(1-2):135-157.

Nieuwenhuis P (1994) Environmental implications of just-in-time supply in Japan - Lessons for Europe? Logistics Focus, April 1994, 2-4.

Nolan K (1998) With distributors in mind, Northwestern embraces VMI. Metal Center News 38(3):32-36.

Olsmats C, Edghill J,and Towill, D.R. (1988) Industrial dynamics model building of a close-coupled productiondistribution system. Engineering Costs and Production Economics 13(4):295-310.

Potter A (2005) The impact of supply chain dynamics on transport. PhD Thesis, Cardiff University.

Potter A, Lalwani CS (2005) Supply chain dynamics and transport: A review. Proceedings of the 10th Logistics Research Network Conference, Plymouth, 353-358.

Potter A, Lalwani C, Hosoda T, Al-Kaabi H (2005) Vendor Managed Inventory in a grocery supply chain: What are the benefits? Proceedings of the 10th International Symposium on Logistics, Lisbon, 541-546.

Stank TP and Goldsby TJ (2000) A framework for transportation decision making in an integrated supply chain. Supply Chain Management: An International Journal 5(2):71-77.

Towill DR (2005) A Perspective on UK Supermarket pressures on the supply chain. European Management Journal 23(4):426-438.

Waller M, Johnson ME, Davis T (1999) Vendor-Managed Inventory in the retail supply chain. Journal of Business Logistics 20(1):183-203. 